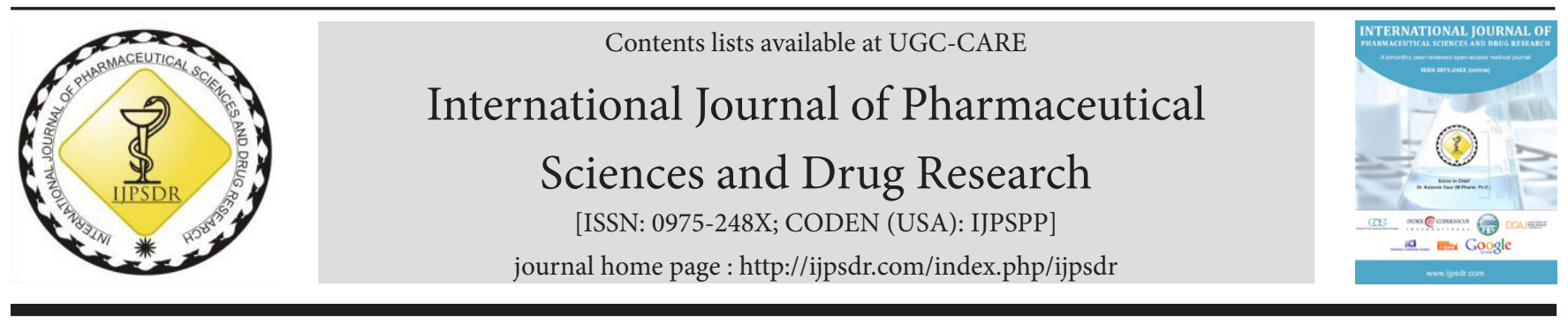

Research Article

\title{
Development of Microemulsion Formulation For Oral Delivery of Rosuvastatin Calcium
}

\author{
Himanshu Paliwal ${ }^{1}$, Ram S. Solanki ${ }^{2}$, Chetan S. Chauhan ${ }^{1}$ \\ ${ }^{1}$ Faculty of Pharmacy, Bhupal Nobles' University, Udaipur-313001, Rajasthan, India \\ ${ }^{2}$ Shrinathji Institute of Pharmacy, Nathdwara-313301, Rajasthan, India
}

\author{
ART ICLE INFO \\ Article history: \\ Received: 14 October, 2019 \\ Revised: 08 January, 2020 \\ Accepted: 09 January, 2020 \\ Published: 30 January, 2020 \\ Keywords: \\ Drug release, Microemulsion, Oral \\ delivery, Rosuvastatin calcium. \\ DOI: \\ 10.25004/IJPSDR.2020.120106
}

\begin{abstract}
A B S T R A C T
The purpose of conducting this study was to prepare an oral microemulsion formulation of rosuvastatin calcium (RC) to improve its water solubility. Oil in water microemulsion was formulated using oleic acid, Tween 80, and Polyethylene Glycol-400 (PEG-400) as oil, surfactant, and co-surfactant, respectively. The ideal proportion of surfactant: co-surfactant (Smix) was chosen by constructing pseudoternary diagrams. The microemulsion formulations, which proved to be stable after thermodynamic stability testing, were further evaluated for physical characteristics. Selected formulations were evaluated for droplet size, zeta potential, polydispersity index, viscosity, and \% drug content. Results suggested that optimized microemulsion formulation (F2) was thermodynamically stable and clear, having a droplet size of $74.29 \mathrm{~nm}$ and zeta potential of -18.44. In-vitro dissolution study for optimized microemulsion was performed using a dialysis bag method and cumulative \% drug release was determined. The result from the release study was indicative of improved solubility of RC, which may serve to boost up the oral bioavailability of the drug.
\end{abstract}

\section{INTRODUCTION}

Hyperlipidemia is a serious ailment, including abnormal blood levels of various lipids, specifically cholesterol, triglycerides, phospholipids, and/or plasma lipoproteins. ${ }^{[1]}$ It is one of the primary factors leading to atherosclerosis and several other serious cardiovascular diseases (CVDs). ${ }^{[2]}$ The incidences of elevated lipid concentrations in hyperlipidaemic individuals are of major concern among the healthcare community because fatalities from CVDs have increased recently. ${ }^{[3]}$ The repercussions could be severe to such an extent that CVDs in the coming year will globally become a leading cause of death. ${ }^{[4]}$

Patients with higher lipid levels who are prone to CVDs are subjected to treatment with lipid-lowering drugs or making lifestyle changes, such as dietary modifications, increased physical activity, etc. to regulate lipid levels in the body. ${ }^{[5-6]}$ Statins are effective in the reduction of low- density lipoproteins and the prevention of developing CVDs in individuals at risk. ${ }^{[7-8]}$ Rosuvastatin is a highly potent statin drug, is used to reduce the levels of cholesterol, triglycerides, etc. in patients with hyperlipidemia. This can help to lower the progression of atherosclerosis, which is considered to be a major risk factor for CVDs. ${ }^{[9]}$ Currently, only tablets and capsules are available in the market as oral formulations of RC. ${ }^{[10]}$ It is a BCS class II drug, and the main hindrance with its oral formulations is poor aqueous solubility. Thus, a novel formulation of $\mathrm{RC}$ is needed to resolve its solubility and bioavailability issues. ${ }^{[11]}$

A microemulsion is a transparent dispersion of a colloidal nature containing a system of oil, water, and surfactants, which is generated spontaneously and thermodynamically stable. ${ }^{[12]}$ Lipid-based microemulsions can be used to enhance the aqueous solubility of RC, which can improve its oral bioavailability. ${ }^{[13-14]}$ Many reports in the

\footnotetext{
*Corresponding Author: Mr. Himanshu Paliwal

Address: Faculty of Pharmacy, Bhupal Nobles' University, Udaipur-313001, Rajasthan, India

Email $\bowtie$ : himanshupaliwal.2013@rediffmail.com

Tel.: +91-7737619052

Relevant conflicts of interest/financial disclosures: The authors declare that the research was conducted in the absence of any commercial or financial relationships that could be construed as a potential conflict of interest.

Copyright (C) 2020 Himanshu Paliwal et al. This is an open access article distributed under the terms of the Creative Commons AttributionNonCommercial-ShareAlike 4.0 International License which allows others to remix, tweak, and build upon the work non-commercially, as long as the author is credited and the new creations are licensed under the identical terms.
} 
literature suggested that the use of microemulsions can enhance oral bioavailability of loaded drugs by preventing enzymatic degradation and improving membrane permeability. ${ }^{[15]}$

The investigation was focussed on preparing and optimizing oral microemulsion of RC by using physicochemical parameters such as percent transmittance, droplet size, zeta potential, viscosity, etc. The selected formulation was then studied for in-vitro release of RC from the microemulsions.

\section{Materials AND METhods}

\section{Materials}

RC was a generous gift from Intas Pvt. Ltd., Ahmedabad, India. Oleic acid, polyethylene glycol, and propylene glycol were procured from Chemco ${ }^{\circledR}$, Chemdyes Corporation (India). Olive oil, castor oil, ethyl oleate, and soyabean oil were from Ozone ${ }^{\circledR}$ International Ltd. (India). Isoprpyl Myristate, Tween ${ }^{\circledR} 20$ (polyoxyethylene 20 sorbitan monolaurate), Tween ${ }^{\circledR} 80$ (polyoxyethylene 20 sorbitan monooleate), $\operatorname{Span}^{\circledR} 80$ (Sorbitan monooleate), Span ${ }^{\circledR} 20$ (Sorbitan monolaurate), ethanol, potassium dihydrogen phosphate were acquired from Central Drug House (P) Ltd. (India). The chemicals used for the investigation were of analytical reagent grade.

\section{Excipient Selection by Using Solubility Studies}

The oil, surfactant, and co-surfactant were selected on the basis of solubility of RC in various excipients. Solubility was analyzed by adding a surplus amount of drug in about $2 \mathrm{~mL}$ of selected excipients by thoroughly blending them in vials using a vortex mixer. The vials were further ultra-sonicated for 72 hours to equilibrate the samples and then centrifuged at 6,000 rpm for 10 minutes. The supernatant fluid obtained was filtered and analyzed for the concentration of RC in samples using an ultraviolet spectrophotometer at $243 \mathrm{~nm} .^{[16]}$

\section{Drug-excipient Compatibility Study}

The surfactants used for the preparation of microemulsion must be evaluated beforehand for their interactions with the drug. For this purpose, a known amount of drug was mixed with a combination of surfactant and co-surfactant (1:1) in a glass vial. The sample was stored for a period of one month at $25^{\circ} \mathrm{C}$ and observed for physical changes like precipitation, crystallization, phase separation, and color change. Chemical incompatibility was checked by performing an assay of drug in the sample using a UV-visible spectrophotometer, and a significant loss of potency (more than 10\%) will serve as a sign of chemical interactions. $^{[17]}$

\section{Development of Pseudoternary Phase Diagrams}

Pseudoternary diagrams were prepared to characterize the microemulsion region and to find out the optimum combination of components (oil, surfactant, and co-surfactant) used for the preparation. The water titration method was used, wherein fixed proportions of surfactant: co-surfactant (Smix), i.e., 1:2, 1:1, and 2:1 $\mathrm{w} / \mathrm{w}$ was taken. Smix and oil were mixed in a ratio of $1: 9$, $2: 8,3: 7,4: 6,5: 5,6: 4,7: 3,8: 2$ and 9:1 and water are added dropwise to each oil-Smix mixture under continuous moderate stirring. The mixtures were assessed visually when it changes from clear to opaque, indicating the traversing from microemulsion to coarse emulsion zone. The plotting pseudoternary diagrams were done using SigmaPlot application Software. ${ }^{[18-19]}$

\section{Characterization of Microemulsions}

\section{Appearance and Clarity}

The appearance was determined by examining the formulation visually under light alternatively against white and black backgrounds for the presence of turbidity. The clarity of microemulsions was determined in terms of \%Transmittance when checked against distilled water. A known amount of formulation was diluted 100 times with distilled water, and \% transmittance is measured using a UV-visible spectrophotometer. ${ }^{[20]}$

\section{Thermodynamic Stability Studies}

Thermodynamic stability studies assessed the physical stability of microemulsion. The formulation was subjected to six heating-cooling cycles between temperatures of $4^{\circ} \mathrm{C}$ and $40^{\circ} \mathrm{C}$ stored for not less than 48 hours. The formulation was then centrifuged at $5000 \mathrm{rpm}$ for 30 minutes, followed by three free thaw cycles at temperatures of $-20^{\circ} \mathrm{C}, 4^{\circ} \mathrm{C}$, and $+25^{\circ} \mathrm{C}$ for not less than 48 hours. ${ }^{[21]}$

\section{Physical Characteristics of Microemulsion}

Droplet Size Distribution and Zeta-potential

For evaluating droplet size and zeta potential, the formulation is first diluted to about ten times with distilled water is agitated gently for about 10 minutes. The resultant emulsion analyzed for distribution of droplet size and zeta potential using laser diffraction, Malvern Instruments, UK. ${ }^{[22-23]}$

- Polydispersivity Index (PDI)

Polydispersivity confers the size range of particles in the system, and the results obtained from droplet size analysis were used to calculate PDI.

- Viscosity Measurement

Viscosity was measured using Brookfield viscometer DVII plus pro, Brookfield engineering laboratory, U.S.A.) at $30^{\circ} \mathrm{C}$ with $60 \mathrm{rpm}$ using spindle LV1. ${ }^{[24]}$

\section{Drug Content}

The drug content of RC microemulsion was estimated by diluting $100 \mu \mathrm{L}$ of the optimized formulation with methanol, and volume was made up to $100 \mathrm{~mL}$. It is followed by computing absorbance of resulted solution at $243 \mathrm{~nm}$ using a UV spectrophotometer. ${ }^{[25]}$ 


\section{In-vitro Drug Release Study}

The In-vitro release study of microemulsion formulation was conducted using a dialysis bag method. Dialysis bag is soaked overnight into a phosphate buffer $\mathrm{pH} 6.8$ as a saturation step before using it for an experimental procedure. It was then filled with about $0.5 \mathrm{~mL}$ of $\mathrm{RC}$ microemulsion, and both the ends of the bag were tied using thread. Dialysis bag containing formulation is set in a dissolution vessel filled with $900 \mathrm{~mL}$ of phosphate buffer pH 6.8 that was maintained $37 \pm 1^{\circ} \mathrm{C}$. The dissolution was carried out, and samples were taken out periodically from the medium. Samples were assayed for the concentration of $\mathrm{RC}$ at predetermined time intervals by using UV spectrophotometer. $^{[26]}$

\section{RESULTS AND DISCUSSION}

\section{Excipient Selection by Using Solubility Studies}

Outcomes of the solubility study of RC are shown in Table 1. Based on the results from solubility studies, oleic acid as an oil phase, Tween 80 as a surfactant, and PEG 400 as a co-surfactant were chosen.

\section{Drug-excipient Compatibility Study}

The surfactants selected from solubility studies were evaluated for compatibility with RC, as a generally very high quantity of surfactants is required in the preparation of microemulsions. The combination of Tween 80: PEG-400 did not show any indications of physical and chemical incompatible reactions, and, therefore, can be further used for the formulation purpose.

\section{Pseudoternary Phase Diagrams}

The water titration method was employed for the assessment of Smix ratios of 1:2,1:1, and 2:1 for their capability to generate a higher microemulsion region (Fig. 1). Noticeably, formulations with 2:1 Smix ratio allow incorporation of more water but limiting the drug solubility. On the other hand, at Smix ratio of 1:2 increased drug solubility, but lesser allowance for the
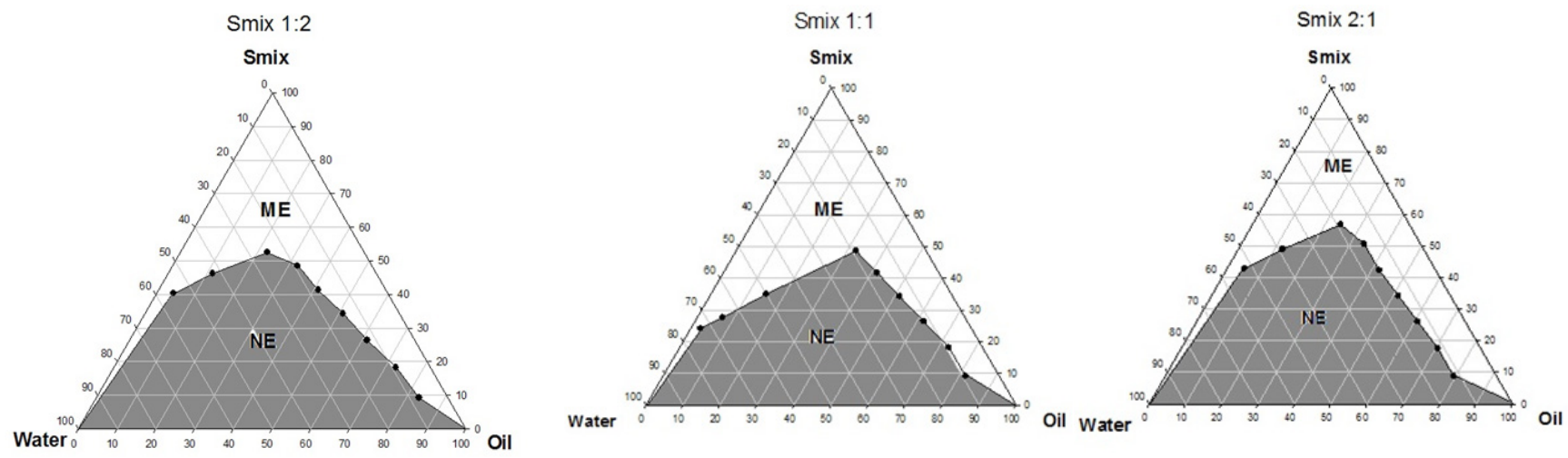

Fig.1: Pseudo-ternary phase diagrams of Oleic Acid (oil), Tween 80: PEG 400 (surfactant: co-surfactant) and water (tween 80: PEG $400=2: 1,1: 1$ and 1:2). ME: Microemulsion Region, NE: Non-microemulsion region

Table 1: Solubility of rosuvastatin calcium in various excipients at $25^{\circ} \mathrm{C}$

\begin{tabular}{ll}
\hline Oils & Drug solubility $(\mathrm{mg} / \mathrm{mL})$ \\
\hline Olive oil & 7.08 \\
Castor oil & 12.13 \\
Isopropyl myristate & 19.74 \\
Ethyl oleate & 15.30 \\
Oleic acid & 46.58 \\
Soyabean oil & 8.26 \\
\hline Surfactants & Drug solubility $(\mathrm{mg} / \mathrm{mL})$ \\
\hline Tween 80 & 59.70 \\
Span 80 & 52.35 \\
Tween 20 & 32.15 \\
Span 20 & 26.4 \\
\hline Co-surfactants & Drug solubility $(\mathrm{mg} / \mathrm{mL})$ \\
\hline Glycerine & 21.306 \\
PEG-400 & 42.56 \\
Propylene glycol & 28.58 \\
Ethanol & 6.36 \\
\hline
\end{tabular}


incorporation of water. In addition to that, the existence of the microemulsion region was relatively higher for ternary plots with the Smix ratio of 1:1 when compared to the other ternary plots and thus selected for further studies. Microemulsions were obtained by mixing an appropriate quantity of RC in oil and adding surfactant and co-surfactant, which is titrated with water add dropwise to the oily phases with magnetic stirring.

\section{Characterization of Microemulsions}

\section{Appearance and Clarity}

Microemulsions selected based on phase diagram were evaluated for appearance and clarity by diluting them with distilled water. They remained clear upon dilution but appeared as transparent yellow in color due to the presence of oils and polysorbates as surfactants. The clarity of microemulsion was quantified in terms of transmittance (\% T). The values of \% of all formulations were higher than 98\%, and therefore microemulsions showed better clarity, which is also indicative of minimal droplet size.

\section{Thermodynamic Stability Studies}

Microemulsions containing a higher concentration of oils showed signs of physical instability and therefore failed thermodynamic stability test. RC microemulsions that conceded stability tests were further evaluated (Table 2).

\section{Physical Characteristics of Microemulsion}

Microemulsions with small droplet sizes are more stable than the larger ones because they are less prone to coalescence and creaming. It was deduced that F2 formulation produced droplets with smallest size. The outcomes of the size distribution study are shown in Table 3.

The zeta potential value asserting stable and deflocculated microemulsion system should ideally be between -10 to $-30 \mathrm{mV}$. Zeta potential results were found in the range of -5 to $-15 \mathrm{mV}$. (Table 3 ) The only formulation which lies in the ideal zeta potential range was F2.
The PDI values were less than 0.3 for F1, F2, and F3, displaying homogeneity of dispersed particles. Contrarily, PDI of F4 was found to be greater than 0.3 .

The viscosities of RC-microemulsions were observed to be within the range of 0.892 to $0.916 \mathrm{cP}$. The data for viscosity determination (Table 3 ) point towards very low viscosities which were expected, because microemulsions have characteristically low viscosity values.

The results of $\%$ drug content in the selected formulations were higher than $98 \%$ of the total amount of drug added. These results revealed the capability of the system for entrapment of a high amount of drug.

\section{In-vitro Drug Release Study}

The analysis of release of drugs from microemulsion formulation is a useful method for predicting its in-vivo behavior. The in-vitro release of RC-Microemulsion was examined for optimized formulation (F2) was performed using a dialysis bag method. It was determined from the experiments that $35.71,65.04$, and $89.63 \%$ of RC was released during 1,3 , and 7 hour, respectively (Fig. 2). The drug release was possibly affected due to very small size of RC-containing dispersed oil globule. The oil globules might act carrier molecules facilitating the diffusion of drugs through the membrane of the dialysis bag.

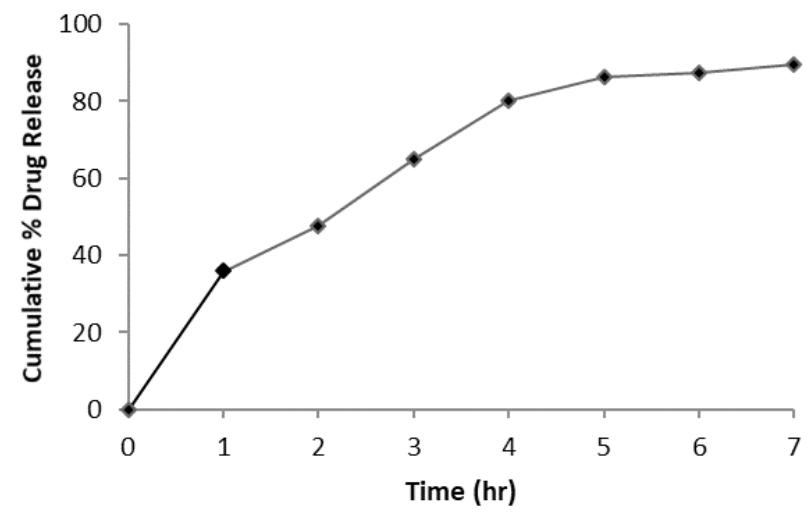

Fig. 2: In-vitro dissolution profile of F2 formulation

Table 2: Compositions of selected microemulsions

\begin{tabular}{lllll}
\hline Component & $F 1$ & $F 2$ & $F 3$ & $F 4$ \\
\hline Rosuvastatin calcium (mg) & 10 & 10 & 10 & 10 \\
Oleic acid (\%) & 5 & 16.5 & 24 & 32.5 \\
Tween $80(\%)$ & 22.5 & 19.25 & 18 & 16.25 \\
PEG-400 (\%) & 22.5 & 19.25 & 18 & 16.25 \\
Water (\%) & 50 & 45 & 40 & 35 \\
\hline
\end{tabular}

Table 3: Physicochemical parameters of RC-microemulsion

\begin{tabular}{lllll}
\hline Parameters & $F 1$ & $F 2$ & $F 3$ & $F 4$ \\
\hline Droplet size (nm) & $152.76 \pm 2.1$ & $74.29 \pm 1.6$ & $136.15 \pm 3.3$ & $159.03 \pm 2.5$ \\
Zeta potential & -7.18 & -18.44 & -10.39 & -5.82 \\
PDI & $0.226 \pm 0.07$ & $0.152 \pm 0.04$ & $0.129 \pm 0.1$ & $0.268 \pm 0.09$ \\
Viscosity (cps) & $0.892 \pm 0.08$ & $0.905 \pm 0.09$ & $0.916 \pm 0.03$ & $0.899 \pm 0.02$ \\
Drug content (\%) & $99.17 \pm 0.24$ & $99.02 \pm 0.59$ & $98.83 \pm 0.93$ & $98.41 \pm 0.73$ \\
\hline
\end{tabular}




\section{CONCLUSION}

This study was undertaken to formulate, develop and optimize microemulsion formulations of RC to manipulate the release characteristics of a poor water-soluble drug. It was evident from the study that microemulsions may be employed to improve the bioavailability of those drugs whose absorption is limited due to their solubility. The ratio of Tween 80: PEG 400 (Smix) and Oleic acid: Tween 80 played an important role in preparing RC loaded microemulsion. To select optimum ratio of excipients, three different combinations of Tween 80 and PEG 400 were analyzed with Oleic acid by using Pseudo ternary phase diagram. The 1:1 ratio of Tween 80: PEG 400 produced a better microemulsion region than $1: 2$ and $2: 1$ ratios. The four formulations from the Smix ratio of 1:1 were selected for further evaluation because of their better stability and ability to incorporate high amount of water.

The selected formulations F1-F4 were further evaluated for droplet size, PDI, zeta potential, viscosity, drug content and in-vitro drug release. The viscosities and $\%$ drug content for all the formulations were similar; however, droplet size and zeta potential results were highly in favor of F2 formulation. From the results obtained, F2 formulation found out to be optimum, which contained oleic acid, Tween 80, PEG 400 and water in 16.5, $19.25,19.25$, and $45 \%$, respectively. The in-vitro release data of F2 showed that $89.63 \%$ of drug released in $7 \mathrm{hr}$, which may also pave its way to improve oral bioavailability of RC. Thus, it can be inferred that stable microemulsion formulations were prepared for oral delivery of RC.

\section{REFERENCES}

1. Mishra PR, Panda PK, Chowdary KA. Evaluation of acute hy polipidemic activity of different plant Extracts in Triton Wr-1339 I induced hyperlipidemia in albino rats. 2011;934:925-934.

2. Austin MA, Breslow J, Hennekens CH, Buring JI, Willett WC, Krauss RM. Low density lipoprotein subclass patterns and risk of myocardial infarction. JAMA. 1988;260:1917-1921.

3. Murphy SL, Xu JQ, KD K. Deaths: Preliminary data for 2010. National vital statistics reports, Table B. Hyattsville, MD: National Center for Health Statistics; 2012.

4. Jorgensen T, Capewell S, Prescott E, Allender S, Sans S, Zdrojewski T. Population-level changes to promote cardiovascular health. Eur. J. Prev. Cardiol. 2013;20(3):409-421.

5. Curioni CC, Lourenco PM. Long-term weight loss after diet and exercise: a systematic review. Int J Obes (Lond). 2005;29:1168-1174.

6. Makris A, Foster GD. Dietary approaches to the treatment of obesity. Psychiatr Clin North Am. 2011;34:813-827.

7. Sever PS, Dahlof B, Poulter NR, et al. Prevention of coronary and stroke events with atorvastatin in hypertensive patients who have average or lower-than-average cholesterol concentrations, in the Anglo-Scandinavian Cardiac Outcomes Trial-Lipid Lowering Arm (ASCOT-LLA): a multicentre randomised controlled trial. Lancet. 2003;361:1149-1158

8. Brugts JJ, Yetgin T, Hoeks SE, et al. The benefits of statins in people without established cardiovascular disease but with cardiovascular risk factors: meta-analysis of randomised controlled trials. BMJ. 2009;338:b2376.

9. Nissen SE, Nicholls SJ, Sipahi I, Tuzcu EM. Effect of very highintensity statin therapy on regression of coronary atherosclerosis: The ASTEROID trial J. Am. Med. Assoc. (2006);295(13):1556-1565

10. Wishart DS, Feunang YD, Guo AC, Lo EJ, Marcu A, Grant JR, Sajed T, Johnson D, Li C, Sayeeda Z, Assempour N, Iynkkaran I, Liu Y, Maciejewski A, Gale N, Wilson A, Chin L, Cummings R, Le D, Pon A, Knox C, Wilson M. DrugBank 5.0: a major update to the DrugBank database for 2018. Nucleic Acids Res. 2017 Nov 8. doi: 10.1093/ nar/gkx1037.

11. Akbari BV, Valaki BP, Mardiya VH, Akbari AK, Vidyasagar G. Enhancement of solubility and dissolution rate of rosuvastatin calcium by complexation with $\beta$ cyclodextrin. Int J Pharm Biol Arch. 2011;2(1):511-520.

12. Callender SP, Mathews JA, Kobernyk K, Wettig SD. Microemulsion utility in pharmaceuticals: Implications for multi-drug delivery International journal of pharmaceutics. 2017;526(1-2):425-442.

13. Garcia-Celma MJ, Azemar N, Pes MA, Solans C. Solubilization of antifungal drugs in water/POE (20) sorbitan monooleate/oil systems. Int J Pharm. 1994;105:77-81.

14. Silva AE, Barratt G, Chéron M, Egito EST, Development of oil-inwater microemulsions for the oral delivery of Amphotericin B, Int. J. Pharm. 2013;454(2):641-648.

15. Sarciaux J, Acar L, Sado P. Using microemulsion formulations for oral drug delivery of therapeutic peptides. Int J Pharm. 1995; 120(2):127-136.

16. Singh G, Pai RS. Trans-resveratrol self-nano-emulsifying drug delivery system (SNEDDS) with enhanced bioavailability potential: optimization, pharmacokinetics and in situ single pass intestinal perfusion (SPIP) studies. Drug Delivery. 2015 May 19;22(4):522-30.

17. Liu R, Water-insoluble drug formulation, CRC press, 2008;2:p. 134

18. Singh AK, Chaurasiya A, Awasthi A, Mishra G, Asati D, Khar RK, et al. Oral bioavailability enhancement of exemestane from selfmicroemulsifying drug delivery system [SMEDDS]. AAPS PharmSciTech. 2009;10(3):906-916.4.10.1208/s12249-009-9281-7

19. Yin YM, Cui FD, Mu CF, Choi MK, Kim JS, Chung SJ, Shim CK, Kim DD. Docetaxel microemulsion for enhanced oral bioavailability: preparation and in-vitro and in vivo evaluation. J Control. Release. 2009;140:86-94.

20. Podlogar F, Gasperlin M, Tomsic M, Jamnik A, Rogac MB. Structural charac - terisation of water-Tween 40/Imwitor 308-isopropyl myristatemicro emulsions using different experimental methods. Int J Pharm. 2004;276(1-2):115-128.

21. Ali MS, Alam MS, Alam N, Siddiqui MR. Preparation, characterization and stability study of dutasteride loaded nanoemulsion for treatment of benign prostatic hypertrophy. Iran J Pharm Res. 2014; 13:1125-1140.

22. Ramesh Shah R, Shripal Magdum Ch, Shivagonda Patil Sh, Shanawaj Niakwade N. Preparation and Evaluation of Aceclofenac Topical Microemulsion. Iran J Pharm Res. 2010;9(1):5-11.

23. Srinivas C, Sagar VS. Enhancing the bioavailability of simvastatin using microemulsion drug delivery system. Asian J Pharm Clin Re 2012;15(4):134e139.

24. Moghimipour E., Salimi A., Eftekhari S. Design and characterization of microemulsion systems for naproxen. Adv. Pharm. Bull. 2013; 3:63-71.

25. Alany RG, Tucker IG, Davies NM, Rades T. Characterizing colloidal structures of pseudo ternary phase diagrams formed by oil/ water/amphiphile systems. Drug Dev Ind Pharm. 2001;27(1): 31-38.

26. Kang BK, Lee JS, Chon SK, Jeong SY, Yuk SH, Khang G, Lee HB, Cho SH. Development of self-microemulsifying drug delivery systems (SMEDDS) for oral bioavailability enhancement of simvastatin in beagle dogs. Int. J. Pharm. 2004;274:65-73. 